\title{
Markers of oxidative and atherogenic processes in individuals with hand-arm vibration syndrome and metabolic disorders
}

\author{
Liudmila Masnavieva \\ ESIMER, \\ Angarsk, Russia \\ Masnavieva_Luda@mail.ru
}

\author{
Irina Kudaeva \\ ESIMER, \\ Angarsk, Russia \\ Kudaeva_Irina@mail.ru
}

\author{
Nadezhda Chistova \\ ESIMER, \\ Angarsk, Russia
}

\begin{abstract}
Changes in the activity of lipid peroxidation processes are observed when exposed to vibration, as well as metabolic syndrome and type 2 diabetes, which are characterized by metabolic disorders. This study is devoted to the assessment of atherogenic and oxidative processes in individuals with hand-arm vibration syndrome in combination with metabolic disorders. We examined the levels of cholesterol, cholesterol in high and low density lipoproteins, oxidized low density lipoproteins, antibodies to them and the thiol status in 59 men with hand-arm vibration syndrome, in 73 people with vibrational disease in combination with metabolic syndrome and in 35 individuals with hand-arm vibration syndrome and type 2 diabetes. It was found that the average value of total cholesterol was higher than the reference level in all groups. A decrease in cholesterol in high density lipoproteins and an increase in cholesterol in low density lipoproteins have been observed in individuals with metabolic disorders. Levels of oxidized low-density lipoproteins and antibodies to them were increased in all groups. Correlation existed between the level of total cholesterol and cholesterol in low density lipoprotein, between the content of oxidized low density lipoproteins and total cholesterol, between the concentration of oxidized low density lipoproteins and cholesterol in low density lipoprotein in all groups. The correlation between the cholesterol level in high lipoproteins and thiol status was disrupted in patients with hand-arm vibration syndrome and metabolic disorders.
\end{abstract}

Keywords - lipids, oxidized lipoproteins, antibodies to oxidized lipoproteins, hand-arm vibration syndrome, metabolic disorders

\section{Motivation and Aim}

Vibration pathology occupies one of the leading positions in the structure of occupational morbidity. A complex of regulatory disorders, changes in oxidative metabolism and oxidative stress develop during hand-arm vibration syndrome (HAVS) and play an important role in its pathogenesis. [1]. Diabetes mellitus (DM) is one of the most common noncommunicable diseases; the number of patients is increasing annually both in Russia and around the world [2]. A complex of disorders in lipid, carbohydrate and other metabolism, which is called metabolic syndrome (MS), appears during the formation of diabetes. It is known that metabolic changes and an increase in the activity of peroxide processes occur in type 2 diabetes and in MS. Lipoproteins and their oxidized forms play an important role in atherogenic processes and in the development of vascular pathology. [3].

This study is devoted to the assessment of oxidative and atherogenic processes in individuals with hand-arm vibration syndrome in combination with metabolic disorders.

\begin{abstract}
Methods
In total, we examined 167 men with HAVS aged 40-66 years. Group I consisted of 59 patients with HAVS, group II of 73 patients with HAVS in combination with MS, group III included 35 individuals with HAVS and type 2 diabetes. The level of total cholesterol and cholesterol in high density lipoproteins (HDL cholesterol) was determined spectrophotometrically. The content of cholesterol in low density lipoproteins (LDL cholesterol) was calculated using the Friedwald formula. We examined the thiol status, levels of oxidized lipoproteins and antibodies to them (oxLDL and antibodies to oxLDL, respectively) in blood serum using enzyme-linked immunosorbent assay. Statistical processing of the results was performed using nonparametric tests (Kruskell-Wallis, Mann-Whitney, Spearman rank correlation). The research results are presented in the form of a median and interquartile range.
\end{abstract}

\section{Results}

When analyzing the lipid profile, it was found that in group II the values of total cholesterol were slightly higher than in groups I and III ( $p=0.038$ and $p=0.079$, respectively) (Table 1 ). The average values of this indicator were higher than the upper reference limit $(5.17 \mathrm{mM} / \mathrm{L})$ in all groups. HDL cholesterol levels in the group of individuals with HAVS without metabolic disorders were higher than in groups II and III ( $p<0.001$ and $p<0.001$ ). The concentration of LDL cholesterol in patients with HAVS and MS was higher than in individuals of group I $(p=0.006)$ and tended to differ compared to group III $(\mathrm{p}=0.026)$. The proportion of individuals with increased LDL cholesterol was $23.3 \%$ in the group of patients with HAVS without metabolic disorders, the frequency of increased levels of this indicator in groups II and III was $38.3 \%(p=0.06)$ and $30.3 \%(p=0.46)$, respectively. The content of oxLDL and the levels of antibodies to them in the blood serum of the subjects did not statistically significantly differ. It should be noted that in all groups the levels of oxLDL and antibodies to oxLDL were elevated (reference values were $117 \mathrm{IU} / \mathrm{L}$ and $30 \mathrm{IU} / \mathrm{ml}$, respectively). This may be due to the binding of antibodies to oxLDL, which is aimed at neutralizing the pathological effect of the last lipoproteins on the vascular wall. The redox status, which was assessed by the level of thiol groups, depending on the presence of metabolic disorders, was not established, it did not differ in the groups. We conducted an analysis of the correlation relationships below. 
TABLE I. Parameters of lipid and thiol status in individuals with hand-arm vibration syndrome and metabolic disorders

\begin{tabular}{|c|c|c|c|c|}
\hline \multirow{2}{*}{ Indicator } & \multicolumn{3}{|c|}{ Group } & \multirow[b]{2}{*}{$p$} \\
\hline & $I$ & II & III & \\
\hline $\begin{array}{l}\text { Total } \\
\text { cholesterol, } \\
\mathrm{MM/л}\end{array}$ & $\begin{array}{l}5.3(4.6- \\
5.9)\end{array}$ & $\begin{array}{l}5.6(5.0- \\
6.1)\end{array}$ & $5.5(4.7-5.8)$ & $\begin{array}{l}0.0 \\
65\end{array}$ \\
\hline $\begin{array}{l}\text { HDL } \\
\text { cholesterol, } \\
\mathrm{MM} / л\end{array}$ & $\begin{array}{c}1.3(1.1- \\
1.6)\end{array}$ & $\begin{array}{c}1.0(0.8- \\
1.4)^{* I}\end{array}$ & $\begin{array}{c}0.9(0.8- \\
1.2)^{* I}\end{array}$ & $\begin{array}{l}0.0 \\
00\end{array}$ \\
\hline $\begin{array}{l}\text { LDL } \\
\text { cholesterol, } \\
\mathrm{MM} / \text { л }\end{array}$ & $\begin{array}{c}3.2(2.3- \\
3.8)\end{array}$ & $\begin{array}{c}3.5(3.2- \\
4.2)^{* I}\end{array}$ & $\begin{array}{c}3.2(2.7- \\
3.9)^{\# I I}\end{array}$ & $\begin{array}{l}0.0 \\
09\end{array}$ \\
\hline $\begin{array}{l}\text { Thiol status, } \\
\text { мкМ/мл }\end{array}$ & $\begin{array}{c}471.2 \\
(418.3- \\
517.4)\end{array}$ & $\begin{array}{c}457.6 \\
(392.5- \\
521.5)\end{array}$ & $\begin{array}{l}425.05 \\
(392.5- \\
482.1)\end{array}$ & $\begin{array}{l}0.5 \\
96\end{array}$ \\
\hline охLDL мЕ/л & $\begin{array}{c}131.1 \\
(104.0- \\
168.5)\end{array}$ & $\begin{array}{c}135.0 \\
(111.3- \\
160.3)\end{array}$ & $\begin{array}{c}131.7(87.7- \\
152.7)\end{array}$ & $\begin{array}{l}0.4 \\
74\end{array}$ \\
\hline $\begin{array}{l}\text { Antibodies to } \\
\text { oxLDL, } \mathrm{ME} / \mathrm{M} Л\end{array}$ & $\begin{array}{c}41.9(32.1- \\
50.8)\end{array}$ & $\begin{array}{c}45.4(39.0- \\
78.8)\end{array}$ & $\begin{array}{l}41.1(28.2- \\
55.6)\end{array}$ & $\begin{array}{l}0.1 \\
38\end{array}$ \\
\hline
\end{tabular}

Notes: $\mathrm{p}$ - is the level of statistical significance of the differences according to the Kruskell-Wallis test; * I - differences are statistically significant compared with group I, $\mathrm{p}<0,016$; \#II - tendency to differences compared with group II, $0.016<\mathrm{p}<0.033$.

It was found that the correlation was between the level of total cholesterol and $\mathrm{LDL}$ cholesterol $(\mathrm{R}=0.77, \mathrm{R}=0.84$ and $\mathrm{R}=0.81 ; \mathrm{p}<0.05$ for groups I-III, respectively), the content of oxLDL and total cholesterol $(\mathrm{R}=0.50, \mathrm{R}=0.47$ and $\mathrm{R}=$ $0.67, p<0.05$ for groups I, II and III), the concentration of oxLDL and LDL cholesterol $(\mathrm{R}=0.68, \mathrm{R}=0.40$ and $\mathrm{R}=0.83$, $\mathrm{p}<0.05$ for groups I-III, respectively) in all groups. We found a negative relationship between the level of HDL cholesterol and thiol status $(R=-0.63 ; p<0.05)$ in the group of individuals without metabolic disorders. This correlation was absent in groups II and III. This may indicate changes in the antioxidant defense system. It should be noted that weak negative associations between the content of oxLDL and antibodies to oxLDL $(\mathrm{R}=-0.33 ; \mathrm{p}<0.05)$ were detected in group II. Increased levels of LDL cholesterol, oxLDL, and the relationship of these indicators may indicate the development of atherogenic processes and increased peroxidation, since oxidized modifications of LDL have proatherogenic properties [4]. The oxLDL can act as autoantigens [5]. A negative correlation between oxLDL and antibodies to them may be due to the fact that a high content of antibodies regulates the level of antigens and can block the absorption of oxLDL by macrophages [6].

Thus, the levels of total cholesterol, oxLDL, and antibodies to oxLDL are increased in individuals with HAVS both with and without metabolic disorders. HDL cholesterol is reduced and LDL cholesterol is elevated in patients with HAVS and metabolic disorders The correlation between the level of HDL cholesterol and thiol status in patients with HAVS and metabolic disorders is disrupted.

\section{REFERENCES}

[1] H. Sakakibara, S. Maeda, Y. Yonekawa Thermotactile threshold testing for the evaluation of sensory nerve function in vibrationexposed patients and workers. Int. Arch. Occup. Environ. Health. 2002. vol. 75, N 1-2, pp. 90-96

[2] E.Z. Golukhova, E.V. Kuznetsova Myocardial revascularization in patients with type 2 diabetes mellitus: An overview of modern techniques. Diabetes mellitus. 2016. vol. 19, N 5, pp. 406-413. (references)

[3] S. Ayilavarapu, Diabetes-Induced Oxidative Stress Is Mediated by Ca+-Independent Phospholipase A2 in Neutrophils. J. Immunol. 2010. .vol. 184, pp. 1507-1515.

[4] J.A. Berliner, G. Subbanagounder, N. Leitinger, A.D. Watson, D.Vora. Evidence for a role of phospholipid oxidation products in atherogenesis. Trends Cardiovasc Med. 2001. Vol. 11, N 3-4, pp.142147.

[5] S. Tsimikas, W. Palinski, J.L. Witztum Circulating autoantibodies to oxidized LDL correlate with arterial accumulation and depletion of oxidized LDL in LDL receptor-deficient mice. Arterioscler Thromb Vasc Biol. 2001. Vol. 21, N 1, pp. 95-100.

[6] P.X. Shaw, S. Hörkkö, S. Tsimikas, M.K. Chang, W. Palinski, G.J. Silverman, et al Human-derived anti-oxidized LDL autoantibody blocks uptake of oxidized LDL by macrophages and localizes to atherosclerotic lesions in vivo. Arterioscler Thromb Vasc Biol. 2001. Vol. 21, pp.1333-1339. 